\title{
Effect of Direct Quenching on Microstructure and Mechanical Properties of a Wear-resistant Steel
}

Hongyu SONG ${ }^{1) \dagger}$, Shunhu ZHANG ${ }^{1)}$, Liangyun $L A N^{1)}$, Canming $L I^{1,2)}$, Haitao $L I U^{1)}$, Dewen $Z H A O^{1)}$ and Guodong WANG ${ }^{1)}$

1) State Key Laboratory of Rolling and Automation, Northeastern University, Shenyang 110819, China

2) Technical Research and Development Center, Laiwu Steel Group, Laiwu 271104, China

[Manuscript received 21 October 2012, in revised form 24 March 2013]

(C) The Chinese Society for Metals and Springer-Verlag Berlin Heidelberg

\begin{abstract}
A wear-resistant steel was hot rolled at the same finish temperature, and subsequently treated with conventional reheat quenching and tempering process (RQ\&T) and direct quenching and tempering process (DQ\&T), respectively. The effect of direct quenching on the microstructure and mechanical properties was investigated in detail by using optical microscope, transmission electron microscope and scanning electron microscope equipped with electron backscattered diffraction. The results showed that the microstructures of both the $\mathrm{RQ}$ and $\mathrm{DQ}$ specimens were complex constituents of lath martensite and lower bainite. Compared with the $R Q$ specimen, the lower bainite content in $D Q$ specimen was much higher. Furthermore, the bainite in the $D Q$ specimen extended into and segmented the prior austenite grains, which can decrease martensite packet size. The proportion of high-angle boundary in the $D Q$ specimen was higher than that in the RQ specimen, which may improve the impact toughness. The carbides in DQ\&T specimen were much finer and distributed even dispersively because direct quenching can retain substantive defects which may provide more nucleation sites for carbide precipitation in the tempering process. Besides, the mechanical properties of DQ and DQ\&T specimens were superior than those subjected to $R Q$ and $R Q \& T$ processes, respectively.
\end{abstract}

\section{KEY WORDS: Direct quenching; Temper; Lower bainite; Martensite packet; Mechanical} properties

\section{Introduction}

Wear-resistant steels have been widely applied in civilian industry such as lining board, toothed plate, hammers and other mechanical parts which require excellent properties ${ }^{[1-3]}$. Conventional reheating quenching and tempering (RQ\&T) process is the general heat treatment to produce wear-resistant steels. By adopting the thermomechanical treatment techniques of controlled rolling and accelerated cooling, it is possible to achieve the desired microstructure tailored to meet specific mechanical properties by applying the direct quenching and tempering (DQ\&T) process $^{[4-8]}$.

In conventional reheat quenching and temper-

† Corresponding author. Ph.D.; Tel: +86 24 83681190; E-mail address: sohoyu@126.com (Hongyu SONG)

DOI: $10.1007 / \mathrm{s} 40195-012-0183-4$ ing (RQ\&T) process, the austenite composition and grain size, which play important roles in determining the ultimate microstructure and mechanical properties, are controlled largely by the austenitizing temperature $^{[9]}$. By contrast, besides the superiorities of simpler process and lower cost by deleting reaustenitizing process, direct quenching allows more control of the austenite condition prior to the transformation. Direct quenching can retain substantive defects while these will vanish in the reaustenitizing process $^{[10]}$. The inherited defects can provide massive nucleation sites for the precipitation in the tempering process, and therefore the precipitates may distribute more dispersively in the matrix ${ }^{[11,12]}$. Moreover, the different cooling rates between the RQ and DQ process may have some effects on the microstructure and properties. Former researchers indicated that the lower bainite has an important influence on the mechanical properties in the complex constituents of 

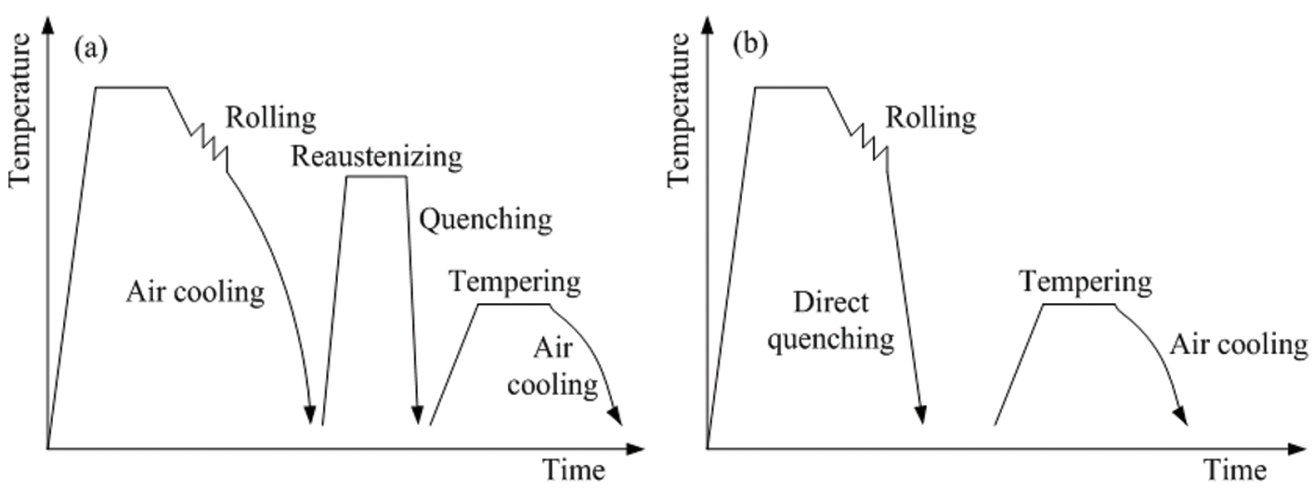

Fig. 1 Schematic representation of different heat-treatment processes: (a) RQ\&T; (b) DQ\&T

the tempered lath martensite and lower bainite ${ }^{[13]}$. The acicular lower bainite extending into the prior austenite grains can decrease the martensite packet size, which increases the proportion of the high-angle boundaries considered as the barriers to deformation and fracture ${ }^{[14]}$. Besides, the lower bainite can remit the stress concentration at the crack tip and accommodate deformation of lower bainite and the adjacent martensite, which can improve the toughness and plasticity ${ }^{[15]}$.

This present paper aimed towards studying the effect of direct quenching on the microstructure and mechanical properties of the tested steel. The correlations between the microstructure and the mechanical properties of the specimens were investigated.

\section{Material and Experimental Procedure}

\subsection{Materials}

The chemical composition (wt.\%) of the tested steel is as follows: $\mathrm{C} 0.17, \mathrm{Mn} 1.3$, Cr 0.35 , Si 0.3 , $\mathrm{P} 0.006, \mathrm{~S} 0.003, \mathrm{Nb} 0.03, \mathrm{~B} 0.0012, \mathrm{Al} 0.025$ and $\mathrm{Fe}$ balanced. The steel was manufactured in a vacuum induction furnace and cast into the ingots.

\subsection{Thermomechanical process}

The ingots with a thickness of $120 \mathrm{~mm}$ were soaked at $1200{ }^{\circ} \mathrm{C}$ for $2 \mathrm{~h}$ and then rolled into $14 \mathrm{~mm}$ thick plates. These plates were then treated with the conventional reheat quenching and tempering process (RQ\&T) and direct quenching and tempering process (DQ\&T), respectively. Fig. 1 shows the schematic representation of two thermomechanical processes. As for the DQ\&T process, the ingot was rolled, directly quenched and then tempered. In the case of RQ\&T process, the ingot was cooled in the air after rolling, reheated to the austenitisation temperature, water quenched and tempered. The quenching temperature of the plates for two quenching procedures was $950{ }^{\circ} \mathrm{C}$. The plates subjected to RQ process were reaustenitized at $950^{\circ} \mathrm{C}$ for $0.5 \mathrm{~h}$ to generate a homo- geneous austenite microstructure. After the quenching process, all the plates were tempered at $250{ }^{\circ} \mathrm{C}$ for $40 \mathrm{~min}$.

\subsection{Tests method}

Specimens for the microstructure observation were polished by standard metallographic procedures and etched with $4 \%$ nital. Microstructural examination was conducted by a LEICA-DMIRM optical microscope $(\mathrm{OM})$. The quenched and tempered martensite structures including the morphology of martensite lath, dislocations and precipitates were observed by a TECNAL G2 transmission electron microscope (TEM). Electron backscattering diffraction (EBSD) system equipped at a scanning electron microscope (SEM) was used to analyze the crystallography characteristics of the specimens. The fracture surface morphology was observed by SEM.

Specimens for the mechanical property tests were cut from the plates and machined. The mechanical properties including tensile strength, elongation and Charpy impact toughness were measured using the average of three experimental results to ensure the accuracy. The tensile specimens were machined according to tensile test standards and the test was conducted with a 5105-SANS computer controlled universal testing machine. As for the Charpy impact test at $-20{ }^{\circ} \mathrm{C}$, an instrumented Instron9250HV tester was applied. Each specimen was cooled to $-25^{\circ} \mathrm{C}$. Therefore, the specimens can be properly positioned on the testing anvil and the interior and exterior temperature can be approximately equilibrated.

\section{Results and Discussion}

\subsection{Effect of direct quenching on microstructure}

The optical micrographs of the specimens are shown in Fig. 2(a) and Fig. 2(b), respectively. Obviously, the microstructures were characterized by lath martensite and lower bainite which distributes along prior austenite grain boundaries. However, distinct 


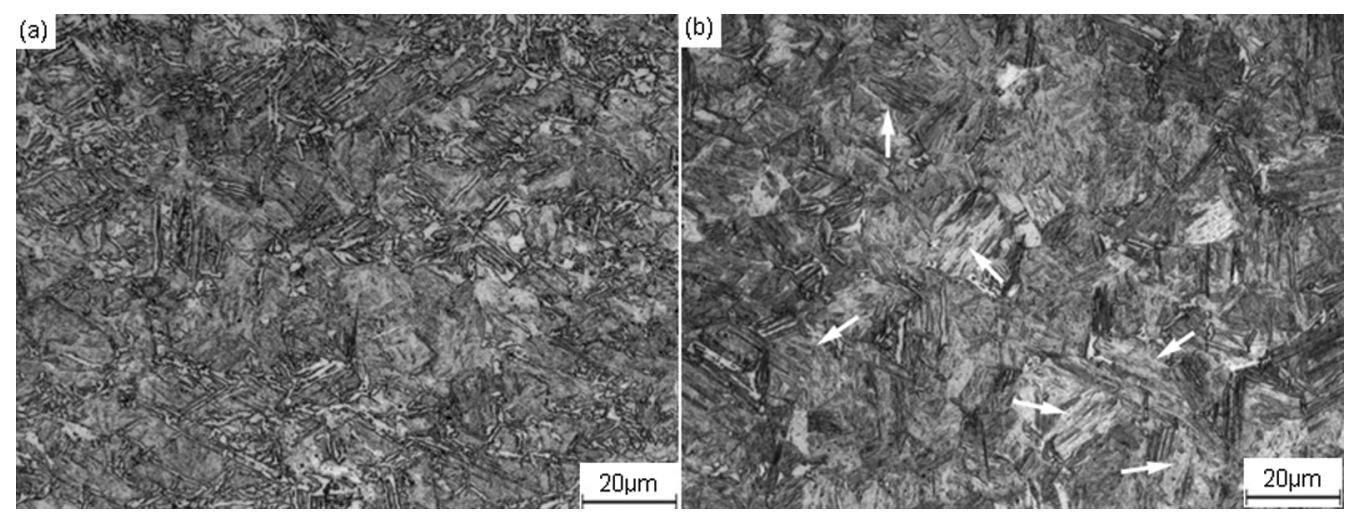

Fig. 2 Optical micrographs showing the microstructure of DQ specimen (a) and RQ specimen (b)

differences can be observed. Firstly, the RQ specimen had irregularly spaced packets compared with the DQ specimens as the white arrows marked in Fig. 2(b). In hot rolling process, the austenite endured severe deformation and the recrystallization process was incomplete prior to direct quenching. Therefore, direct quenching process can preserve the severely deformed microstructure and the orientations of martensite packets are fewer. By contrast, the austenite grains in the RQ specimens recrystallized more completely and the reaustenitizing temperature as well as time were sufficient $\left(950{ }^{\circ} \mathrm{C}\right.$ and $\left.0.5 \mathrm{~h}\right)$ in the reheat quenching process. Consequently, the specimens generated a homogeneous structure within which the orientations of martensite packets were quite diverse ${ }^{[16]}$.

Besides the difference in packets orientation, the bainite content of DQ specimens was found to be higher than that of RQ specimens. Furthermore, the bainite in the RQ specimens distributed along the prior austenite boundary fragmentarily, while the bainite in the DQ specimens extended into the prior austenite grains and segmented them into a few parts as shown in Fig. 2(a). This kind of bainite distribution decreased the martensite packet size as well as the block size, which may influence the mechanical properties to a large extent ${ }^{[17]}$. This can be observed in Fig. 2(a) and the details will be described and explained below. The differences between the bainite content and morphology were mainly related to the cooling rate and the condition of austenite prior to quenching. The cooling rates during different quenching processes were calculated by using the recorded quenching time. It was found that the cooling rate in the DQ process $\left(95^{\circ} \mathrm{C} / \mathrm{s}\right)$ was lower than that in the RQ process $\left(165^{\circ} \mathrm{C} / \mathrm{s}\right)$. That is because the hot rolled plates were sprayed continuously by pressurized water in DQ process, while reaustenitized specimens were put into water and swung back and forth in $\mathrm{RQ}$ process, which can extremely increase cooling rate. Consequently, the lower bainite in DQ process generated along prior austenite grain boundaries and extended into grains due to efficient time for bainite to grow to acicular shape. Because of the high cool- ing rate in $\mathrm{RQ}$ process, temperature passed through bainite forming zone quite fast. Therefore, just little lower bainite generated and this kind of bainite did not segment the prior austenite grains as shown in Fig. 2(b).

\subsection{Effect of direct quenching on the proportion of high-angle boundary}

As known, different thermomechanical processes had various influences on the microstructure which was closely related to the mechanical properties, such as the strength, plasticity and toughness ${ }^{[18]}$. Among the microstructure features, crystallographic characteristic was extremely important in determining some properties. In order to identify the effect of direct quenching on the crystallographic characteristics, EBSD analyses were conducted on the DQ and RQ specimens in this work. The typical orientation color maps and the misorientation maps of the specimens are shown in Fig. 3.

The grain boundaries with different angles in the specimens were detected by EBSD analyses. Because the misorientation between adjacent martensite laths was usually within $2^{\circ}$, misorientation less than $2^{\circ}$ was considered as the interface between adjacent laths or subboundaries rather than the grain boundaries ${ }^{[19]}$. In the misorientation maps, high angle grain boundaries $\left(>15^{\circ}\right)$ were colored in blue lines and the low angle grain boundaries $\left(2^{\circ}-15^{\circ}\right)$ in red lines. As seen in Fig. 3(b) and Fig. 3(d) more red lines were observed in the DQ specimen, however, it still can be conclude that the fraction of high angle grain boundary in the DQ specimen was higher by using the statistics of the misorientation distribution.

Fig. 4 shows the misorientation distribution figures of different specimens and the corresponding fractions of high angle grain boundaries obtained from EBSD analyses are $72 \%$ (DQ specimen) and 63\% (RQ specimen), respectively. As seen in Fig. 4, the fraction of misorientation angle below $15^{\circ}$ in the DQ specimen was apparently lower than that in the RQ specimen. Evidently, the fraction of high angle grain boundaries 


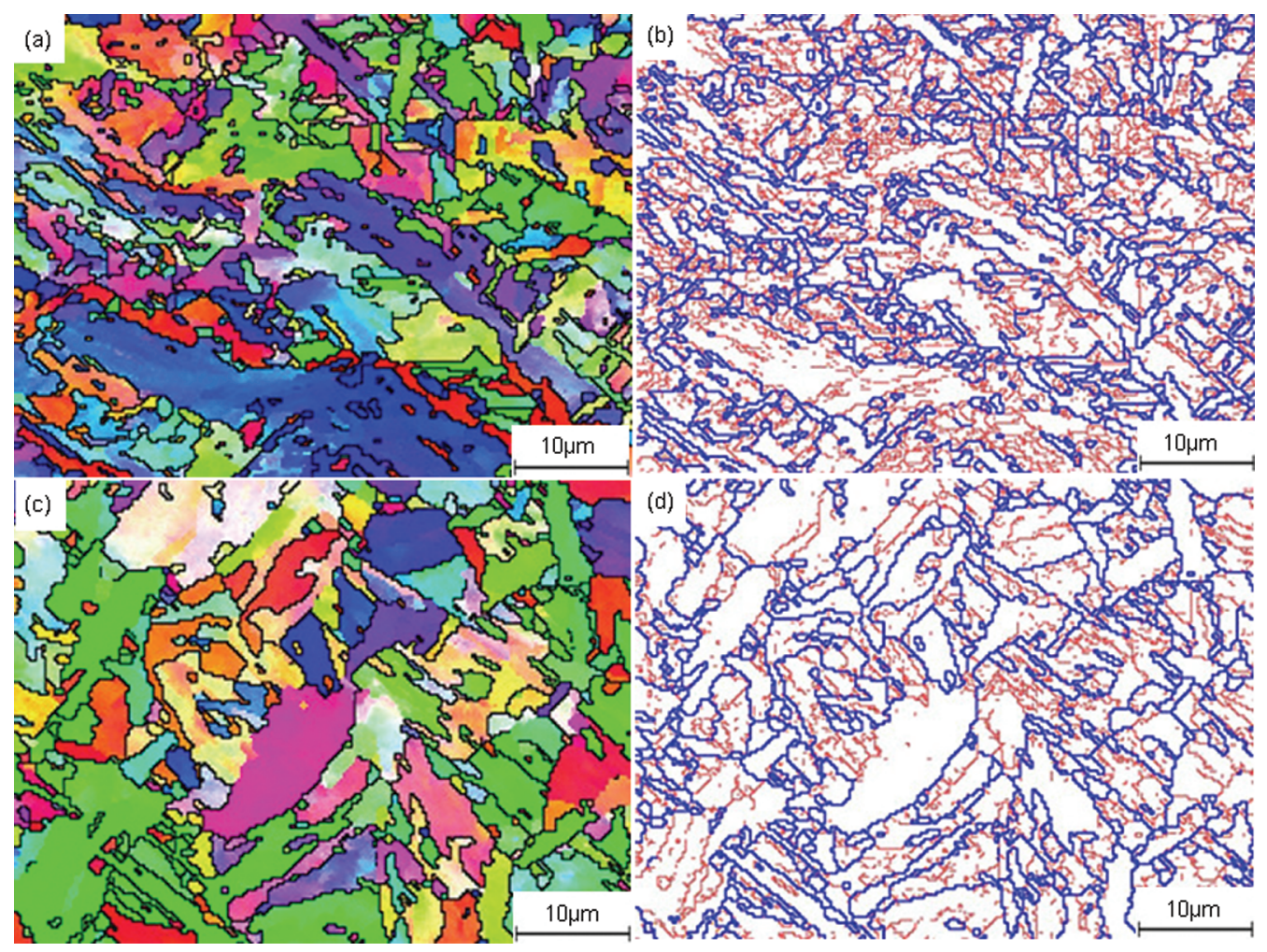

Fig. 3 Orientation color maps (a, c) and misorientation maps (b, d) showing the crystallographic characteristics of the specimens subjected to different quenching processes: (a, b) DQ specimens; (c, d) RQ specimens

in DQ specimen was larger than that in RQ specimen, which indicated that the impact toughness of the DQ specimen should be marginally better because the high angle grain boundaries can act as effective obstacles to cleavage propagation ${ }^{[20,21]}$. Notably, the speculation was in contradiction with the result of impact toughness which will be discussed in detail in the following text. Thus, crystallographic orientation was responsible for the improvement of the impact toughness of the studied steel.

Lath-shaped martensite is the most common martensite morphology in practical high strength steels as well as the heat-treatable steels. The laths are usually grouped into packets and blocks. A packet represents a group of laths with almost the same habit plane, and each packet is further subdivided into blocks, which are groups of laths with almost the same crystallographic orientation ${ }^{[22]}$. The boundaries of packets and blocks are considered to be high angle boundaries and therefore act as barriers to deformation and fracture in martensitic steels. Thus, the refinement of the block and packet sizes can increase the proportion of high angle boundary. Direct quenching the hot deformed austenite termed ausforming is an effective treatment for refining the martensitic structure. Morito et al. ${ }^{[23]}$ reported that both the packet size and block width in Fe- $18 \% \mathrm{Ni}$ maraging steel decrease using the ausforming treatment. A decrease in the packet size by ausforming was also observed in lath martensite in $\mathrm{Fe}-9 \mathrm{Ni}-\mathrm{C}$ steels by Miyamoto et $a l^{[22]}$ As discussed above, the size of austenite prior to the direct quenching decreased because of the lower bainite extending into the prior austenite, which can reduce the block and packet sizes. Consequently, the proportion of high angle boundaries increased as shown in Fig. 4 and EBSD analyses.

\subsection{Effect of direct quenching on fine structures}

The effect of quenching on the fine structure was investigated by a transmission electron microscope (TEM). It was found that the average lath spacing in both RQ and DQ specimens is almost the same. That is because the main factor influencing the lath size was the quenching temperature ${ }^{[9,24]}$. Although the dislocation density in DQ specimen was expected to be higher because the dislocations were reserved, it was hard to observe distinct difference of dislocation density. However, the effect of the quenching on the carbide precipitation during tempering process can be observed distinctly.

Fig. 5 shows the TEM images of the DQ\&T specimen. Because of tempering at low temperature, the morphology of prior martensite was keeped quite completely. The martensite laths arranged parallelly and the average lath spacing was found to be about $0.2 \mu \mathrm{m}$ (Fig. 5(a)). High density dislocations and flake-like carbides can be observed as shown in Fig. 5(b) and Fig. 5(c), respectively. Related researches indicated that the carbides nucleated inside the martensite laths 

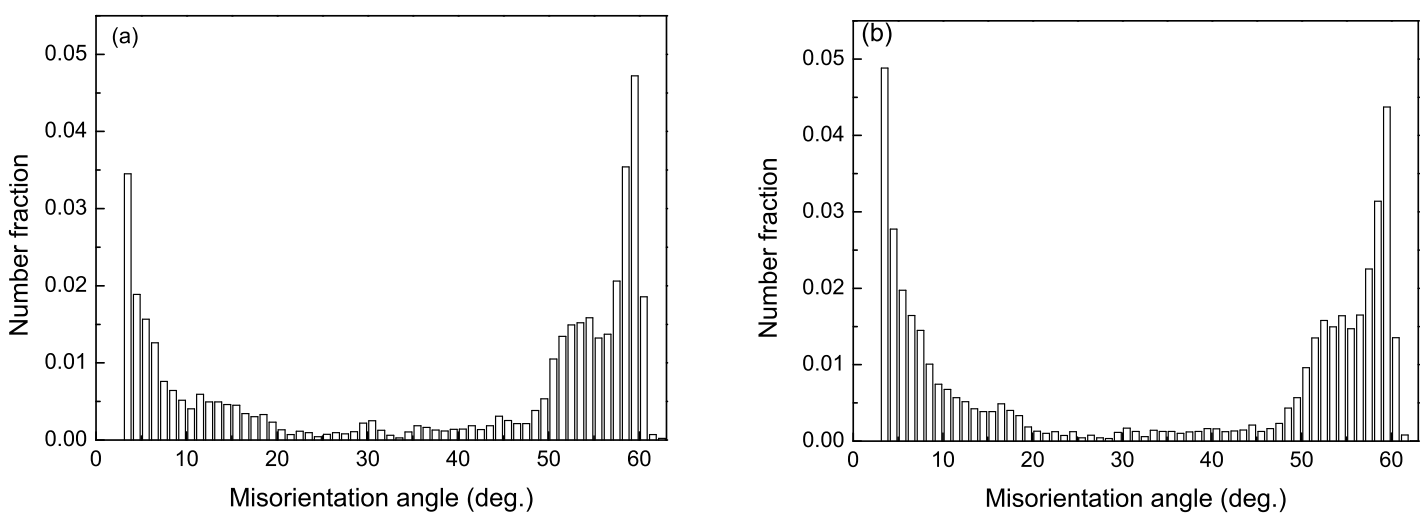

Fig. 4 Misorientation distribution figures of DQ specimen (a) and RQ specimen (b)
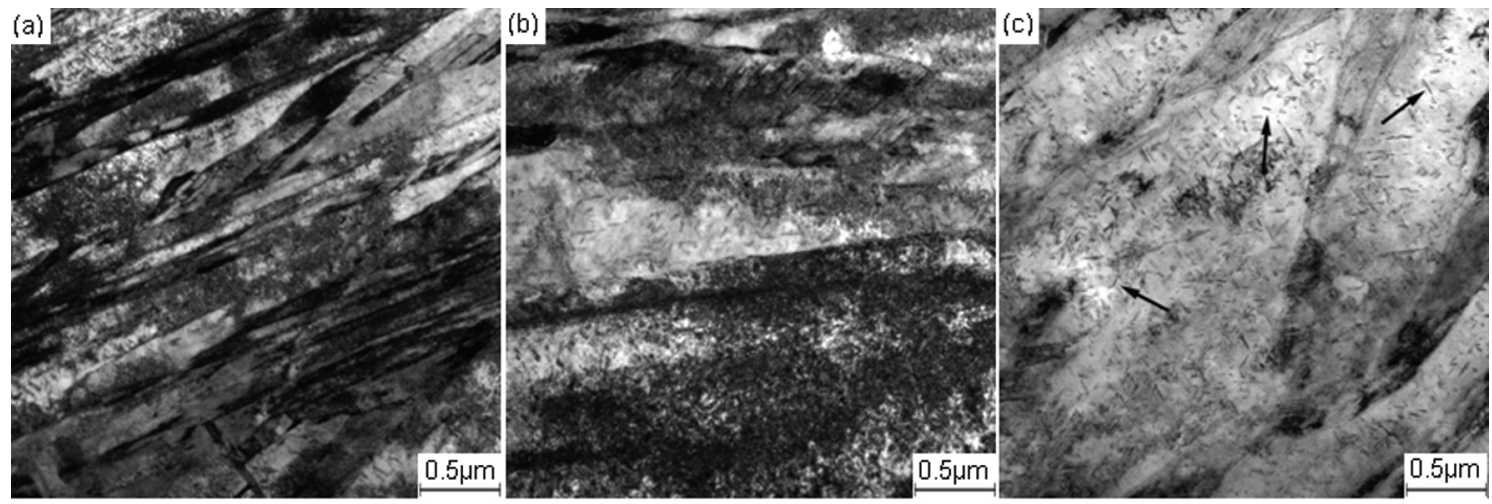

Fig. 5 TEM images showing the morphology of martensite laths (a), morphology of dislocation structure (b) and morphology of carbides precipitation (c) in DQ\&T specimen
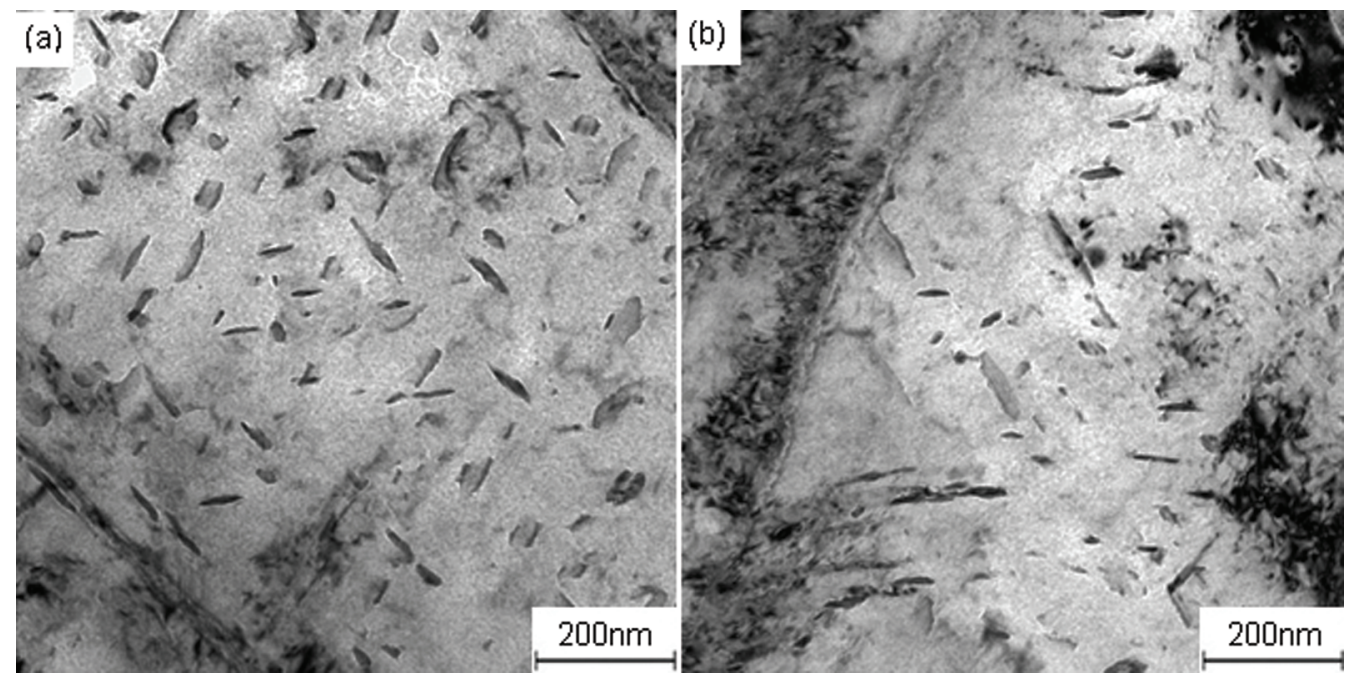

Fig. 6 TEM images showing carbide precipitation of DQ specimen (a) and RQ specimen (b)

and growed into flakiness along the habit plane (110) in low temperature tempering and these carbides had definite crystallographic relationship with the matrix ${ }^{[25]}$. As the arrows marked, the carbides with at least three different extending directions can be observed in Fig. 5(c).
Fig. 6 shows the carbide morphology and distribution in different quenched specimens. In TEM micrographs, flake-like carbides about 50-100 nm long can be observed. These carbides were considered as the precipitates aroused by the auto-tempering during quenching process. It was found that there were more 
Table 1 The variation of mechanical properties of specimens subjected to different processes

\begin{tabular}{ccccc}
\hline Process & $R_{\mathrm{m}}(\mathrm{MPa})$ & El $(\%)$ & Hardness $(\mathrm{HB})$ & $A_{\mathrm{kv}}(\mathrm{J})$ \\
\hline DQ & 1465 & 11.2 & 467 & 61 \\
RQ & 1293 & 11.0 & 441 & 26 \\
DQ\&T & 1388 & 11.4 & 459 & 84 \\
RQ\&T & 1354 & 11.2 & 447 & 37 \\
\hline
\end{tabular}

carbides distributed in the matrix of DQ specimen. Since Aborn ${ }^{[26]}$ discovered the experimental phenomenon of auto-tempering in 1956, Thomas and Speich et al. ${ }^{[27-29]}$ have studied the mechanism of autotempering in detail. It was found that the carbon had the ability to cluster in dislocations and precipitate as carbides in quenching process while the $M_{\mathrm{s}}$ temperature of steel was higher than room temperature. That is because the free energy of the system can be reduced in this process. Researches indicated that the degree of auto-tempering was related to $M_{\mathrm{s}}$ temperature and the cooling rate, i.e., the auto-tempering appeared easily under the condition of high $M_{\mathrm{s}}$ temperature with low cooling rate. Fast cooling rate can shorten the time between $M_{\mathrm{s}}$ temperature and room temperature as a result of which the carbon had no enough time to transfer and precipitate. Thus, the auto-tempering can be inhibited.

According to the measurement by a thermal dilatometer, $M_{\mathrm{S}}$ temperature of tested steel was about $445^{\circ} \mathrm{C}$ which was much higher than the room temperature. Therefore, the auto-tempering will emerge in the quenching process in this work. Because of relatively low cooling rate in the direct quenching, the degree of auto-tempering was higher in the DQ specimens. Much carbon may dissolve from the martensite matrix, cluster around the dislocation and precipitate in the form of carbides. However, the RQ process can inhibit the auto-tempering because of the relative high cooling rate. Consequently, the amount of carbides in the DQ specimens was obviously superior to that in the RQ specimens. Moreover, the carbides in the DQ specimens distributed more dispersively compared with those in the RQ specimens. Because the substantive defects preserved in the direct quenching provided dispersive sites for carbides precipitation during the auto-tempering process ${ }^{[11,12]}$. The carbides will prefer to precipitate in these sites and generate a more dispersive distribution.

\subsection{Effect of direct quenching on mechanical proper- ties}

Table 1 shows the variation of the mechanical properties of the specimens subjected to different thermomechanical processes. As seen, the ultimate tensile strength of the DQ and DQ\&T specimens were higher than those of the RQ and RQ\&T specimens, respectively. Besides, the elongation, hardness and impact toughness of the specimens were accordant with the tendency reflected in the strength test results. Especially, the impact toughness of the DQ and DQ\&T specimens was much higher than those of RQ and RQ\&T specimens. However, the ultimate tensile strength of specimens presented different regularity in the DQ and RQ steels. When tempered at $250{ }^{\circ} \mathrm{C}$ after direct quenching, the UTS of specimens decreased while that of the reheat quenched and tempered specimens increased. Despite the measurement errors, the hardnesses of different specimens show the same regularity as the ultimate tensile strength.

Fig. 7 shows the impact curves and total impact absorbed energy, crack initiation absorbed energy and crack propagation absorbed energy of the DQ\&T specimens and those of RQ\&T specimens. As observed, the impact toughness of the DQ\&T specimen was superior to that of RQ\&T specimens. Both of the crack initiation energy and crack propagation energy of DQ\&T specimen were higher than the values of RQ\&T specimen.
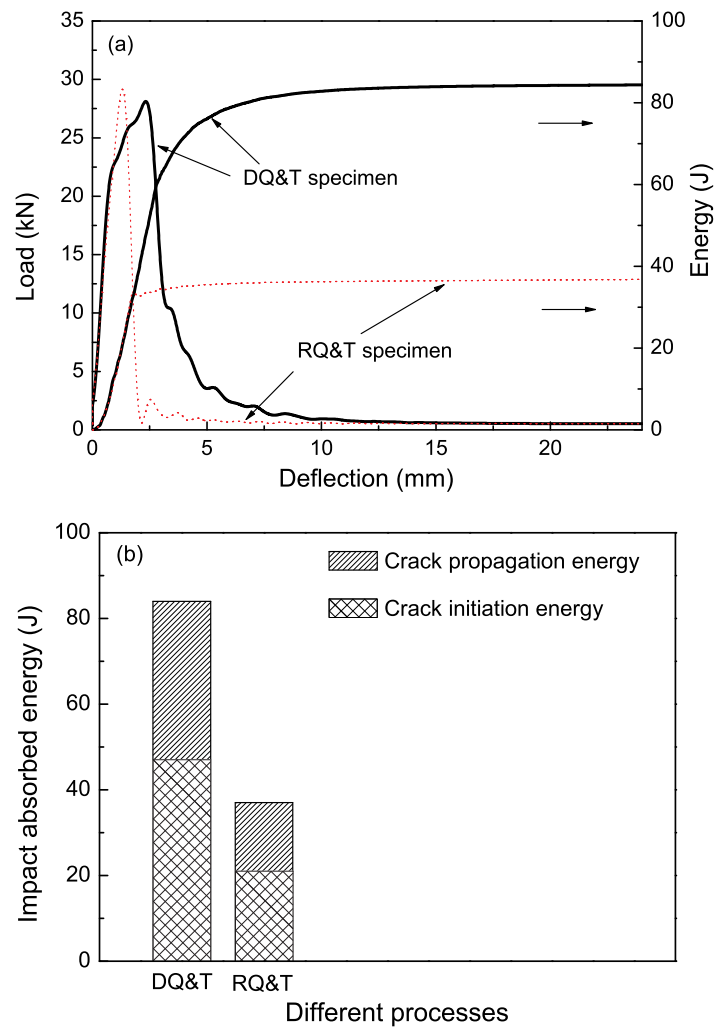

Fig. 7 The images showing the load and impact energy vs. deflection curves (a) and the crack initiation and propagation absorbed energy (b) of DQ\&T and RQ\&T specimens 


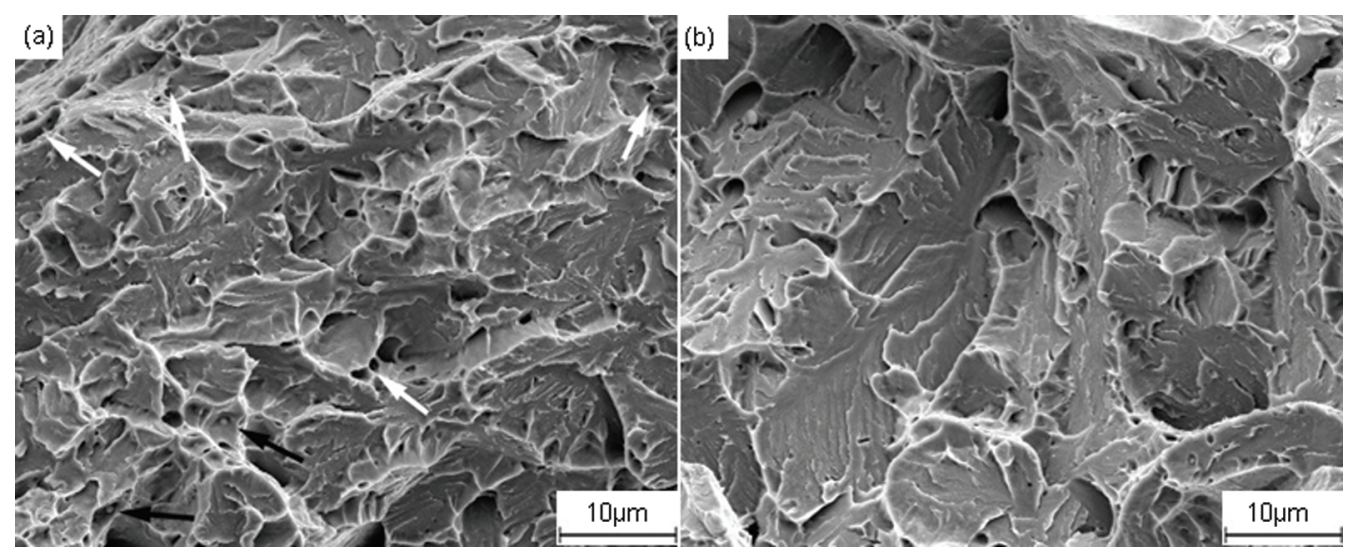

Fig. 8 SEM images showing fracture surface morphology of DQ\&T specimen (a) and RQ\&T specimen (b)

Fig. 8 compares the fracture surface morphologies of the DQ\&T and RQ\&T specimens. Obviously, both of the specimens displayed quasi-cleavage fracture mode, however, distinct differences can be observed. Some ductile fracture bands with lots of small ductile dimples exhibited on the fractograph of DQ\&T specimen and the unit quasi cleavage facet was much smaller. Besides, the fractograph of the DQ\&T specimen contained high density 'river' shaped patterns of which the branches were quite a lot and extended windingly. By contrast, the main part of the fracture surface in RQ\&T specimen was cleavage fracture with large size of unit cleavage facets and the river patterns were straight and had fewer branches.

\subsection{Discussion}

Hardness is one of the most important properties related to the abrasive resistance of materials. Rabinowicz et al. ${ }^{[30]}$ studied abrasive wear under many conditions and established the relationship between hardness and abrasive resistance. The corresponding equation is expressed as Eq. (1).

$$
w=k \cdot \frac{P}{H}
$$

where $w$ is wear rate, $k$ is a coefficient, $P$ is the load and $H$ is the hardness of material. Eq. (1) indicates that wear rate $w$ is inversely proportional to the hardness $H$ under the circumstance of fixed load $P$.

The analysis of wear process indicated that the main wear mechanisms in the abrasive wear are cutting wear and plastic deformation wear. The effect of hardness on these two wear mechanisms will be expounded respectively. As for the cutting wear, the hard surface of the material can prevent abrasive from pressing into the surface and therefore can hinder the material from cutting and removing. While the material was soft, the abrasive may easily be pressed into and move upon the surface, which can result in heavy wear loss. In the case of plastic deformation wear, the abrasive impacted the material surface continuously and caused plastic deformation. The embossmen will emerge around the pits aroused in the impact process. In the process of wear, embossmen endured the impact of the abrasive all the time. Finally, the work hardened material may crack and spall. As for the hard material, it was hard for the abrasive causing pits and embossmen and therefore the material loss caused by plastic deformation wear will be reduced. Consequently, it can be concluded that the hardness had great influence on the abrasive resistance of materials.

The relationship between the mechanical properties and the microstructure is complicated for tested steel in this work. According to the optical and SEM microstructures, both of the DQ and RQ specimens exhibited complex constituents of lath martensite and lower bainite. Researchers indicated that the strength of complex constituents of lath martensite and lower bainite was superior to that calculated by using mixture principle ${ }^{[13]}$. Besides, the lower bainite were surrounded by the martensite matrix. When subjected to external load, the lower bainite endured three dimension compress stress, which can improve the plasticity by accommodating the deformation of bainite and adjacent martensite ${ }^{[17]}$. The lower bainite can remit the stress concentration at the crack tip and prompted the cracks to change the propagation direction ${ }^{[13]}$. The effect of improving the strength, elongation and impact toughness aroused by the lower bainite was related to the content. The content of lower bainite in the DQ specimens was higher. Therefore, the mechanical properties of the direct quenched specimens were superior compared with those of the RQ specimens.

In the forming process, the acicular lower bainite extended into and segmented the prior austenite grains into a few parts, which can effectively decrease the austenite grain size. Consequently, the size of the martensite packet considered as effective grain in the martensite steels was reduced. In lath martensite, the block and packet structures, because of largely common crystallographic orientation of the parallel component laths within the blocks and packets, be- 
came the effective grain structures which may control the deformation ${ }^{[24]}$. Some researchers indicated that the strength improvement aroused by the reduction of effective grain size accorded with the Hall-Petch equation:

$$
\sigma_{\mathrm{y}}=\sigma_{0}+k d^{-1 / 2}
$$

Consequently, while the martensite packet size decreases, the yield strength of the martensite steels increases. That is because small effective grain size can improve the ductility and hardness. The reduction of packet size can also have an effect on the impact toughness. Because the decrease of the packet size increases the proportion of high-angle boundaries considered as barriers to the deformation and fracture in martensitic steels ${ }^{[31]}$. The lower bainite in the DQ specimens can improve the proportion of high-angle boundaries as the EBSD results shown. Consequently, the impact toughness of the direct quenched specimens was greatly improved compared with those RQ specimens. It should be noted that the two reasons above can also explain the superior properties of the DQ\&T specimen.

The direct quenching can retain substantive defects generated in the hot rolling process, which can promote the precipitation of the carbides and other precipitates in the tempering process. Fine carbides and other precipitated precipitate around the dispersed defects ${ }^{[11,12]}$. These dispersed precipitates can restrain the dislocation motion and crack propagation ${ }^{[32.33]}$. Hence, the ultimate tensile strength, hardness and impact toughness of the specimens were greatly improved. By contrast, the carbides in the RQ\&T specimens distributed heterogeneously, which cannot engender strong effect of improving the strength, hardness and impact toughness. Moreover, the condition of carbide precipitation was also the reason why the UTS of DQ specimens decreased after tempering while that in RQ specimens increased. As discussed above, DQ specimens generated lots of carbides in auto-tempering process while the carbides in RQ specimens were little. That is because most of the carbon in RQ specimens is retained in solution as result of relatively high cooling rate. When tempered at $250{ }^{\circ} \mathrm{C}$, the saturated carbon in RQ specimens dissolved from the martensite matrix and precipitated as carbides, which improved UTS to a great extent. However, the carbides formed in the DQ specimens within auto-tempering process started to coarsen. The coarsening of carbides weakened the effect of carbides on the inhibition of dislocation motion and crack propagation, which may decrease the tensile strength and hardness ${ }^{[34]}$. Zhou et al. investigated auto-tempering process in a low carbon martensite steel. Their studies indicated that there are no distinct differences between microstructural characteristic in fully auto-tempered steel and that in low tempering steel. Besides, the mechanical properties including strength, ductility, hardness and toughness of fully auto-tempered steel were superior to those of lower tempering steel ${ }^{[35]}$.

In general, the effect of microstructure on the mechanical properties is complicated. In the case of certain composition, the mechanical properties of steels are mainly influenced by the microstructure controlled by the thermomechanical processes. Therefore, different characteristics of various processes can be applied to make specimens with a variety of mechanical properties. In the present study, the effect of the bainite content on mechanical properties, the influence of auto-tempering on carbide precipitation and other problems are still lack of clear understanding. Much effort should be attributed to achieve the overall understanding.

\section{Conclusions}

(1) The microstructure of the DQ\&T specimens exhibits complex constituents of lath martensite and lower bainite. The lower bainite distributes along prior austenite grain boundaries, extends into the austenite grains and segments them into a few parts.

(2) Direct quenching process can retain the substantive defects of deformed austenite, which can promote the carbides to precipitate dispersively in the tempering process. These dispersed carbides have strong effect on preventing crack propagation and improving the impact toughness.

(3) The lower bainite in the tested steel can improve the mechanical properties. The acicular lower bainite reduces the martensite packet size and therefore improve the proportion of high-angle boundary. Besides, the lower bainite can improve plasticity by deforming to accommodate the deformation of the lower bainite and the adjacent martensite.

\section{Acknowledgements}

This study was financially supported by the National Natural Science Foundation of China (Nos. 51074052 and 51004035).

\section{REFERENCES}

[1] K.S. Luo and B.Z. Bai, Mater. Des. 31 (2010) 2510.

[2] Z.Q. Jiang, J.M. Du and X.L. Feng, J. Iron Steel Res. Int. 13(1) (2006) 57.

[3] M.X. Wei, S.Q. Wang, L. Wang and K. Chen, J. Iron Steel Res. Int. 18(10) (2011) 47.

[4] S.K. Dhua and S.K. Sen, Mater. Sci. Eng. A 528 (2011) 6356.

[5] F.B. Pickering, Proc. Int. Conf. on HSLA Steels Technology \& Applications, Philadelphia, Pennsylvania, 3-6 Oct., 1983.

[6] T. Tanaka, Proc. of Int. Conf. on High Strength Low Alloy Steels, Wollongon, Australia, 1984.

[7] N. Shikanai and M. Suga, Proc. Symp. on Physical Metallurgy of Direct-Quenched Steels, Chicago, Illinois, 2-4 Nov, 1992. 
[8] S.K. Dhua, D. Mukerjee and D.S. Sarma, Metall. Mater. Trans. A 34 (2003) 241.

[9] Y.L. Zhao, J. Shi, W.Q. Cao, M.Q. Wang and G. Xie, J. Zhejiang Univ. Sci. A (Appl. Phys. Eng.) 11 (2010) 776.

[10] R.K. Weiss and S.W. Thompson, Proceedings of the Symposium on Physical Metallurgy of Directquenched Steels, Warrendale, USA, 1992.

[11] T. Abe, M. Kurihara, H. Tagawa and K. Tsukada, Trans. Iron. Steel. Inst. Jpn. 27 (1987) 478.

[12] M. Fujioka, A.Yoshie, Y. Onoe and K. Okamoto, Speich. Symp. Proc., Montreal, Quebec, Canada, 25-28 Oct, 1992.

[13] Y.J. Song, J.T. Lu, J.H. Liu, L. Shen, Q.C. Rao and H.J. Zhou, Trans. Met. Heat Treatment 3(1) (1982) 11. (in Chinese)

[14] Z. Guo, C.S. Lee and J.W. Morris, Acta Mater. 52 (2004) 5511.

[15] Reza, A. Lara and R. Reed-Hill, Physical Metallurgy Principles, CENGAGE Learning, Stamford, 2009, p.700.

[16] J. Qiu, X. Ju, Y. Xin, S. Liu, Y.L. Wang, H.B. Wu and D. Tang, J. Nucl. Mater. 407 (2010) 189.

[17] Y.J. Guo and J.F. Huang, Trans. Met. Heat Treatment 12(1) (1991) 8. (in Chinese)

[18] C. Ouchi, ISIJ 41(5) (2001) 42.

[19] L.L. Yun, CH.L. Qiu, P. Zhou, D.W. Zhao, C.M. Li, X.H. Gao and L.X. Du, Acta Metall. Sin. (Engl. Lett.) 24 (2011) 473.

[20] A.M. Guo, R.D.K. Misra, J.B. Liu, L. Chen, X.L. He and S.J. Jansto, Mater. Sci. Eng. A 527 (2010) 6440.

[21] M. Diaz-Fuentes, A. Iza-Mendia and I. Gutierrez, Metall. Mater. Trans. A 34 (2003) 2505

[22] G. Miyamoto, N. Iwata, N. Takayama and T. Furuhara, Acta Mater. 58 (2010) 6393.

[23] S. Morito, I. Kishida and T. Maki. J. Phys. IV France 112 (2003) 453

[24] G. Krauss, Mater. Sci. Eng. A 273-275 (1999) 40.

[25] L.G. Hu and X.W. Xie, Heat Treatment of Steels, Northwestern Polytechnical Press, Xi'an, 2004, p.169 (in Chinese).

[26] R.H. Aborn, Trans. ASM 48 (1956) 51.

[27] T. Swarr and G. Krauss, Metall. Mater. Trans. A 7 (1976) 41.

[28] S.K. Das and G. Thomas, Metall. Mater. Trans. B 1 (1970) 325.

[29] G.R. Speich and W.C. LesLie, Metall. Mater. Trans. B 3 (1972) 1043.

[30] E. Rabinowicz, L.A. Dunn and P.G. Russel, Wear 4 (1961) 345

[31] H. Liebowitz, Fracture, New York and London Academic Press, 1969.

[32] G.C. Hwang, S. Lee, J.Y. Yoo and W.Y. Choo, Mater. Sci. Eng. A 252 (1998) 256.

[33] B. Ouchi, Iron Steel Inst. Jpn. Int. 41 (2001) 542.

[34] H.J. Zhou, Y.J. Li and J.Y. Qi, International Congress on Heat Treatment of Materials, Shanghai, China, 1983.

[35] J.Y. Qi, Y.L. Li and H.J. Zhou, J. Xi'an Jiaotong Univ. 18 (1984) 9. 